\title{
GOLD and the fixed ratio
}

This article was published in the following Dove Press journal:

International Journal of COPD

24 September 2012

Number of times this article has been viewed

Jørgen Vestbo

University of Manchester, Manchester, UK
Correspondence: Jørgen Vestbo Respiratory Research Group, ERC Building, 2nd Floor, University Hospital, South Manchester, NHS Foundation Trust, Southmoor Road, Manchester M23 9LT, UK

Email jorgen.vestbo@manchester.ac.uk

\section{Dear editor}

I read with interest the paper entitled "Diagnosis of airway obstruction in the elderly: contribution of the SARA study" by Sorino et al in a recent issue of this journal. ${ }^{1}$ Being involved in the Global Initiative for Obstructive Lung Diseases (GOLD), it is nice to see the interest sparked by the GOLD strategy document. However, in the paper by Sorino et al, there are a few misunderstandings around GOLD and the fixed ratio (forced expiratory volume in 1 second/forced volume vital capacity $<0.70$ ) that need clarification.

The study examines airflow limitation in the healthy elderly and comments on the insufficiency of the GOLD diagnostic criteria for COPD. However, GOLD refers to making a clinical diagnosis of COPD in subjects with relevant exposures and/or symptoms compatible with COPD, and was never intended to provide guidance on how to diagnose airflow limitation in epidemiology, and has never been in favor of screening, and particularly not for healthy subjects with no or minimal harmful exposures. Therefore, the premise for the analyses and comments on the appropriateness of GOLD in this context seems questionable. If the purpose was to examine the value of diagnostic criteria for studying COPD in epidemiologic surveys, it would have been appropriate to reference the report of the recent European Respiratory Society task force on epidemiology advocating use of the lower limit of normal in that setting. ${ }^{2}$

\section{Disclosure}

The author reports no conflicts of interest in this letter.

\section{References}

1. Sorino C, Battaglia S, Scichilone N, et al. Diagnosis of airway obstruction in the elderly: contribution of the SARA study. Int J Chron Obstruct Pulmon Dis. 2012;7:389-395.

2. Bakke PS, Rönmark E, Eagan T, et al. Recommendations for epidemiological studies on COPD. ERS task force report. Eur Respir J. 2011;38:1261-1277. 


\section{Authors' response}

\author{
Claudio Sorino ${ }^{1,2}$ \\ Salvatore Battaglia' \\ Nicola Scichilone' \\ Claudio Pedone ${ }^{3}$ \\ Raffaele Antonelli-Incalzi ${ }^{3}$ \\ Duane Sherrill ${ }^{4}$ \\ Vincenzo Bellia'
}

'Biomedical Department of Internal and Specialist Medicine, Section of Pulmonology, University of Palermo, Italy; ${ }^{2}$ Division of Pulmonology, S Anna Hospital, Como, Italy; ${ }^{3}$ Chair of Geriatrics, University Campus Bio-Medico, Roma, Italy; ${ }^{4} \mathrm{Mel}$ and Enid Zuckerman College of Public Health, University of Arizona, Tucson, AZ, USA

\section{Correspondence: Claudio Sorino}

University of Palermo, via Trabucco 180, 90146 Palermo, Italy

Tel +39329408 1729

$\mathrm{Fax}+39916891857$

Email claudiosorino@libero.it

We thank Dr Vestbo for his interest in our manuscript "Diagnosis of airway obstruction in the elderly: contribution of the SARA study" and for the opportunity to clarify some points. As mentioned in the title and aims, the intent of the paper is to offer a contribution to the open issue of identification of airway obstruction in elderly people. ${ }^{1}$

We agree with Dr Vestbo about the utility of distinguishing between the clinical and functional aspects of chronic obstructive pulmonary disease (COPD). We stress that, until the term COPD is used, diagnosis needs clinical evidence of a chronic pulmonary disease and functional evidence of airway obstruction. Given that symptoms compatible with COPD are very frequent in the elderly, a careful evaluation of spirometric data is critical in the diagnostic workup of these patients.

The most recent GOLD guidelines recommend using the fixed ratio of forced expiratory volume in 1 second/forced volume vital capacity $\left(\mathrm{FEV}_{1} / \mathrm{FVC}\right)<0.70$ to define airflow limitation. ${ }^{2}$ The SARA cohort findings show that about $15 \%$ of healthy subjects aged $>65$ years may have an $\mathrm{FEV}_{\mathrm{l}} /$ FVC $<0.70$. Therefore, just as not all those subjects with cough and dyspnea have COPD, not all those with an $\mathrm{FEV}_{1} /$ FVC $<0.70$ have COPD. Moreover, while GOLD guidelines generically suggest using a fixed $\mathrm{FEV}_{1} / \mathrm{FVC}$ ratio of $<0.70$ in the elderly to address the risk of overdiagnosis, ${ }^{2}$ we propose that 0.65 and 0.67 (for men and women, respectively) could represent preferable thresholds for identifying subjects with airway obstruction in such a population. These values correspond to the lower limit of normal, calculated as the fifth percentile of a normal frequency distribution, according to recommendations from the American Thoracic Society/ European Respiratory Society Task Force. ${ }^{3}$ It is important to note that even this method includes a proportion of error, because it assumes that $5 \%$ of a healthy reference population is categorized as "abnormal."

In agreement with the letter by Dr Vestbo and with GOLD guidelines, our study was never intended to offer guidance in how to diagnose airflow limitation in epidemiology, and does not propose screening for COPD in healthy subjects without significant exposure to noxious agents. Indeed, we never mentioned the word "screening," and only refer to "epidemiology" in terms of the need for epidemiological surveys to confirm and extend our observations. Therefore, our intent was not "to examine the value of diagnostic criteria for studying COPD in epidemiologic surveys" as assumed by Dr Vestbo. On the contrary, "the aim of the present study was to provide additional information for determination of the most appropriate spirometric criteria for confirming airway obstruction in the elderly..." in daily clinical practice.

The major focus of our study is the diagnosis of COPD in everyday practice. In this scenario, overestimation of airway obstruction would lead to inappropriate prescription of respiratory drugs, which could be potentially harmful for patients who do not need them.

In conclusion, we recognize the value of the GOLD initiative for COPD in offering a regularly updated document supporting the diagnosis, management, and prevention of a disease with a worldwide high relevance. At the same time we are in favor of using the lower limit of normal for $\mathrm{FEV}_{1} / \mathrm{FVC}$ to define airflow limitation in everyday clinical practice.

\section{Disclosure}

The authors report no conflicts of interest in this letter.

\section{References}

1. Sorino C, Battaglia S, Scichilone N, et al. Diagnosis of airway obstruction in the elderly: contribution of the SARA study. Int J Chron Obstruct Pulmon Dis. 2012;7:389-395.

2. Global Initiative for Chronic Obstructive Lung Disease. Global strategy for the diagnosis, management and prevention of COPD, 2011. Available from: http://www.goldcopd.org/. Accessed May 20, 2012.

3. Pellegrino R, Viegi G, Brusasco V, et al. Interpretative strategies for lung function tests. Eur Respir J. 2005;26:948-968. 
International Journal of COPD

\section{Publish your work in this journal}

The International Journal of COPD is an international, peer-reviewed journal of therapeutics and pharmacology focusing on concise rapid reporting of clinical studies and reviews in COPD. Special focus is given to the pathophysiological processes underlying the disease, intervention programs, patient focused education, and self management protocols.

\section{Dovepress}

This journal is indexed on PubMed Central, MedLine and CAS. The manuscript management system is completely online and includes a very quick and fair peer-review system, which is all easy to use. Visit $\mathrm{http}: / /$ www.dovepress.com/testimonials.php to read real quotes from published authors.

Submit your manuscript here: http://www.dovepress.com/international-journal-of-copd-journal 